\title{
Eye movements enhance memory for individuals who are strongly right-handed and harm it for individuals who are not
}

\author{
KeITH B. LYLE \\ University of Louisville, Louisville, Kentucky \\ Jessica M. Logan \\ Rice University, Houston, Texas \\ AND \\ Henry L. Roediger III \\ Washington University, St. Louis, Missouri
}

\begin{abstract}
Subjects who make repetitive saccadic eye movements before a memory test subsequently exhibit superior retrieval in comparison with subjects who do not move their eyes. It has been proposed that eye movements enhance retrieval by increasing interaction of the left and right cerebral hemispheres. To test this, we compared the effect of eye movements on subsequent recall (Experiment 1) and recognition (Experiment 2) in two groups thought to differ in baseline degree of hemispheric interaction - individuals who are strongly right-handed (SR) and individuals who are not (nSR). For SR subjects, who naturally may experience less hemispheric interaction than nSR subjects, eye movements enhanced retrieval. In contrast, depending on the measure, eye movements were either inconsequential or even detrimental for nSR subjects. These results partially support the hemispheric interaction account, but demand an amendment to explain the harmful effects of eye movements for nSR individuals.
\end{abstract}

Recent research suggests a surprising way to enhance retrieval on a memory test: repeatedly move one's eyes left and right before the test. In comparison with subjects who kept their eyes still for $30 \mathrm{sec}$ immediately before test, subjects who made repetitive, horizontal saccadic eye movements for an equal duration exhibited more accurate recognition (Christman, Garvey, Propper, \& Phaneuf, 2003, Experiment 1; Parker \& Dagnall, 2007) and recall (Christman, Propper, \& Dion, 2004, Experiment 2) of word lists (see also Christman et al., 2003, Experiment 2).

Why do horizontal saccades enhance retrieval? Citing evidence that lateral saccades produce sustained activation of the contralateral hemisphere (Bakan \& Svorad, 1969), Christman et al. (2003) proposed that alternating left-right movements increase bihemispheric activation, which leads to greater or more efficient hemispheric interaction, which in turn benefits retrieval. At present, there is little direct evidence that bilateral saccades increase hemispheric interaction (but see Propper, Pierce, Bellorado, Geisler, \& Christman, 2007), but, if they do, there is theoretical and empirical cause to believe it would enhance retrieval. Theoretically, complex retrieval tasks such as free recall and difficult recognition tests are thought to depend on hemispheric interaction (Johnson \& Raye, 2000) because they simultaneously activate regions in both left and right prefrontal cortex (Nolde, Johnson, \& Raye, 1998). Empirically, greater hemispheric interaction has been linked to superior retrieval in comparisons of groups that differ in such interaction. For example, individuals with intact hemispheric commissures show better retrieval than do split-brain patients (Phelps, Hirst, \& Gazzaniga, 1991; Zaidel \& Sperry, 1974). More germane to the present investigation, neuroanatomical findings suggest that individuals who are strongly right-handed (SR) may experience less hemispheric interaction than individuals who are not (nSR) because the major pathway for interaction - the corpus callosum - is smaller in the former than in the latter (Cowell, Kertesz, \& Denenberg, 1993; Habib et al., 1991; Witelson, 1985; but for failures to find differences, see Jäncke \& Steinmetz, 2003; Kertesz, Polk, Howell, \& Black, 1987). Accordingly, recent studies have documented inferior explicit memory in SR versus nSR individuals (Christman, Propper, \& Brown, 2006, Experiment 1; Christman et al., 2004, Experiment 1; Lyle, Mc-

K. B. Lyle, keith.lyle@louisville.edu 
Cabe, \& Roediger, in press; Propper, Christman, \& Phaneuf, 2005).

If eye movements enhance retrieval by increasing hemispheric interaction (Christman et al., 2003), then the manipulation should differentially affect groups that differ in baseline interaction. A group with less interaction, like SR individuals, may benefit from eye movements more than a group with greater interaction, like nSR individuals, because members of the former group have a larger margin for increases in interaction. To test this hypothesis, we performed an eye-movement manipulation with SR and nSR individuals and tested free recall (Experiment 1) and old/new recognition (Experiment 2). We predicted that eye-movement enhancement on these measures would be greater for SR than for nSR individuals. Hence, we were interested primarily in the interaction of handedness and eye movements as it affects retrieval accuracy. Prior studies have not addressed this issue: The only study to manipulate both handedness and eye movements (Christman et al., 2006, Experiment 2) was concerned with the self-reported age of retrieved childhood memories, which was not verified by the researchers.

\section{EXPERIMENT 1}

\section{Method}

Subjects. Subjects were 142 Washington University students $(87$ females), of which 2 in the eye-movement and 1 in the no-movement condition were excluded from analyses because their false recall was abnormally high (3.8-6.0 SD above the mean). The remaining 139 subjects were classified as nSR or SR by a process described in the Procedure section. Fifty-four subjects were classified as nSR and 85 as SR. Of the nSR subjects, 28 were assigned to the eye-movement and 26 to the no-movement condition. For SR subjects, the corresponding numbers were 41 and 44.

Materials. Handedness was assessed via the Edinburgh Handedness Inventory (Oldfield, 1971), on which respondents reported their handedness behavior for 10 everyday activities (e.g., combing hair, throwing). The response options (and corresponding point values) are always left $(-10)$, usually left $(-5)$, no preference $(0)$, usually right $(+5)$, and always right $(+10)$. Scores range from -100 to +100 .

Stimuli for the recall procedure were 100 words of low-tomedium frequency according to the English Lexicon Project (Balota et al., 2002). From these, two lists of 50 words each were created and matched on word frequency, word length, and number of syllables per word.

For the eye-movement condition, a white dot appeared on a computer screen against a black background. The dot alternated between the left and right sides of the screen (approximately $27^{\circ}$ of visual angle) once every $500 \mathrm{msec}$ for $30 \mathrm{sec}$. For the no-movement condition, a colored dot appeared in the center of the screen and cycled through six colors once every $500 \mathrm{msec}$ for $30 \mathrm{sec}$.

Procedure. Upon arrival at the laboratory, subjects were assigned randomly to the eye-movement or no-movement condition, without regard to handedness. (Subjects were also assigned randomly to study one of the two word lists, but list did not have a main effect on any dependent variable and did not interact with any other factor [all $\left.F_{\mathrm{s}}<1\right]$ and therefore is not considered further.) Subjects first completed the Edinburgh Handedness Inventory and then studied the word list with instructions to learn the words for a later test. Words were presented randomly one at a time on a computer screen at a rate of $2 \mathrm{sec} /$ word with a 500-msec interstimulus interval. Immediately after study, subjects engaged in the eye-movement or no-movement activity for $30 \mathrm{sec}$. Subjects in the eye-movement condition were in- structed to move their eyes to follow the dot, and subjects in the nomovement condition were told to watch the dot change color without moving their eyes. The experimenter observed that all subjects followed the instructions. Finally, immediately after the pretest activity, all subjects recalled the list of words on a lined sheet of paper.

Before data analysis, subjects were classified as nSR or SR on the basis of their Edinburgh Handedness Inventory score. Following Christman et al.'s (2004, Experiment 1) procedure, subjects were classified as nSR if their score was below the median for all subjects $(+80$; range, -100 to +100$)$ and SR if their score was equal to or above the median.

\section{Results and Discussion}

Alpha for all analyses was .05.

Correct recall. Correct recall was the number of studied words recalled by each subject. Group means were analyzed in a 2 (handedness: nSR or SR) $\times 2$ (pretest activity: eye movement or no movement) between-subjects ANOVA. Figure 1 shows that there was a clear interaction between handedness and eye movements, although the effect only approached conventional significance $\left[F(1,135)=2.61, p<.11, \eta_{\mathrm{p}}^{2}=.02\right]$. Nevertheless, planned independent-samples $t$ tests indicated that SR subjects recalled significantly more studied words following eye movements $(M=15.4)$ than following no movement $(M=12.4)[t(83)=2.20, p=.03]$, whereas for $n S R$ subjects, recall was similar whether they moved their eyes $(M=13.8)$ or $\operatorname{did} \operatorname{not}(M=14.2)[t(52)=0.15, p=.82]$. Thus, as predicted, eye movements benefited SR more than they did nSR subjects.

False recall. False recall was the number of nonstudied words, or extralist intrusions, recalled by each subject and was analyzed in the same manner as correct recall. The interaction of handedness and pretest activity was significant $\left[F(1,135)=9.35, p=.003, \eta_{\mathrm{p}}^{2}=.07\right]$, and is apparent in Figure 2. For SR subjects, eye movements $(M=$ $.51)$ produced significantly lower false recall than did no movement $(M=.93)[t(83)=2.01, p=.048]$, but the reverse effect occurred for nSR subjects, whose false recall was significantly greater following eye movements $(M=$

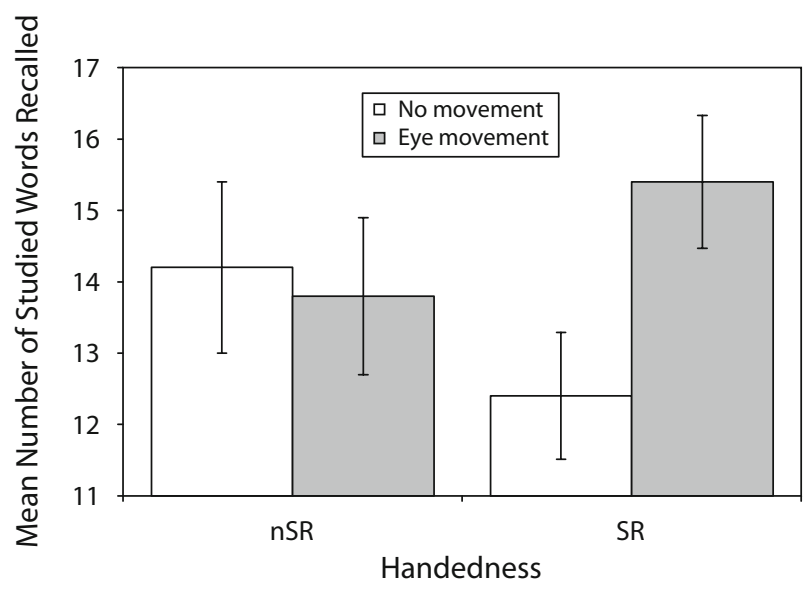

Figure 1. Mean number of studied words recalled in Experiment 1 as a function of handedness and pretest activity. Error bars represent \pm 1 standard error. 


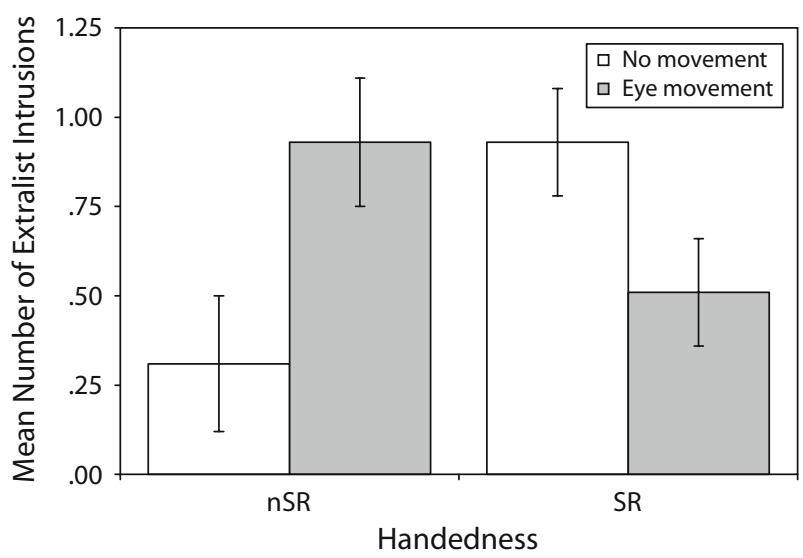

Figure 2. Mean number of extralist intrusions in Experiment 1 as a function of handedness and pretest activity. Error bars represent \pm 1 standard error.

.93) than following no movement $(M=.31)[t(52)=2.29$, $p=.026]$. Hence, on this measure, eye movements not only failed to benefit nSR subjects as much as SR subjects, they actually harmed nSR subjects.

Handedness and memory. Propper et al. (2005) examined differences between $\mathrm{nSR}$ and SR individuals in recall of a random word list in the absence of an eye movement manipulation. For continuity, we compared nSR and SR subjects in our no-movement condition. Replicating Propper et al. (2005), we found that nSR subjects recalled more studied words $(M=14.2)$ and fewer extralist intrusions $(M=$ .31 ) than did SR subjects ( $M \mathrm{~s}=12.4$ and .93 , respectively). The difference was significant for false recall $[t(68)=2.72$, $p=.008]$, but not correct recall $[t(68)=1.23, p=.22]$ (see Christman et al., 2004, for a similar pattern). These results provide further evidence of an $\mathrm{nSR}$ advantage on some measures of explicit memory (Lyle et al., in press).

\section{EXPERIMENT 2}

Experiment 2 explored whether the interaction of handedness and eye movements observed in free recall extended to recognition. We also included two additional pretest activities. In one, subjects performed up-down/vertical eye movements, instead of left-right/horizontal ones, to determine whether both types of saccade enhance retrieval, or only horizontal ones. Christman et al.'s (2003) hemispheric interaction account assumes that only horizontal saccades increase bihemispheric activation and hence only they should enhance retrieval. In past research, the effect of vertical saccades on recognition has been mixed: In Parker and Dagnall (2007), they produced accuracy that did not differ from that for no movement and was significantly lower than that for horizontal movements, but, in Christman et al. (2003, Experiment 1), accuracy in the vertical condition was intermediate between that for the no-movement and horizontal conditions and did not differ reliably from either. In light of the finding from Experiment 1 that eye movements have different effects on nSR and SR individu- als, one concern about these comparisons of vertical and horizontal saccades is that they did not control the ratio of nSR to SR subjects in the two conditions; thus, it is possible that the vertical condition appeared to produce poorer retrieval only because more nSR subjects were assigned to it. In Experiment 2, we again compared vertical and horizontal movements but controlled for handedness.

In another condition, we allowed subjects to make natural, spontaneous eye movements prior to retrieval, in order to test whether repetitive saccadic eye movements enhance retrieval relative to a more naturalistic control condition as opposed to the rather artificial nomovement condition.

\section{Method}

Subjects. Subjects were 154 Washington University students (97 females) who did not participate in Experiment 1. Subjects were classified as nSR or SR as in Experiment 1 and, again, the median Edinburgh score was +80 (range $=-100$ to +100 ). The numbers of SR subjects assigned to the horizontal-, vertical-, no-, and spontaneous-movement conditions were $23,25,19$, and 22 , respectively. For nSR subjects, the corresponding numbers were 15 , 14, 19, and 17.

Materials. The study list was composed of the 50 mediumfrequency words used in Experiment 1. For the test, 50 additional words were chosen to serve as lures. Each lure was associated with or related to one of the studied words (targets). For example, for the target boyfriend, the lure was girlfriend. Associated and related lures were used to increase difficulty and because eye movements have been found to improve discrimination between studied and associated words (Christman et al., 2004, Experiment 2; Parker \& Dagnall, 2007).

For the horizontal- and no-movement activities, the displays were the same as in Experiment 1. The vertical-movement display was identical to the horizontal one, except that the dot alternated between the top and bottom of the screen, instead of the left and right. In the spontaneous-movement condition, the screen simply went dark.

Procedure. Subjects viewed 50 words presented in random order at a rate of $1.5 \mathrm{sec} /$ word with a $500-\mathrm{msec}$ interstimulus interval, with instructions to learn the words for a later test. Next, there was a 10-min retention interval filled with an unrelated task. Then subjects performed one of four pretest activities. The horizontal- and no-movement conditions were identical to those in Experiment 1, and the vertical-movement condition differed from the horizontalmovement condition only in the direction of eye movements. In the spontaneous-movement condition, subjects were told that they had $30 \mathrm{sec}$ to get ready for a memory test on the studied words. During this time, the computer screen went dark. The experimenter did not attempt to control subjects' behavior, but did observe it. Subjects performed various mundane behaviors that involve spontaneous eye movements, such as stretching and glancing around the room.

Immediately after the pretest activities, subjects took the selfpaced old/new recognition test. Fifty targets and 50 lures appeared on the screen one at a time in random order. Subjects pressed "Z" on a keyboard to respond "old" and "X" to respond "new."

\section{Results and Discussion}

Our initial measure of recognition accuracy was $d^{\prime}$. Preliminary analysis in the two eye-movement conditions revealed that direction of saccades did not significantly affect recognition $[F(1,73)=1.15, p=.29]$ and did not interact with handedness $(F<1)$. Vertical movements, rather than being inferior to horizontal ones (Christman et al., 2003, Experiment 1; Parker \& Dagnall, 2007), pro- 
duced numerically higher $d^{\prime}$. The no- and spontaneousmovement conditions produced similar accuracy $(F<1)$. Therefore, for statistical analyses, the horizontal and vertical conditions were combined into a single eye-movement group and the no- and spontaneous-movement conditions were combined into a single control group.

Recognition was analyzed in the same way as were the recall measures in Experiment 1 and, as can be seen in Figure 3, handedness and eye movements interacted $\left[F(1,150)=7.09, p=.009, \eta_{\mathrm{p}}^{2}=.045\right]$. For SR subjects, $d^{\prime}$ was significantly greater following eye movements $(M=1.44)$ than following the control activities $(M=1.04)[t(87)=2.53, p=.013]$, but, for nSR, eye movements $(M=.96)$ produced nonsignificantly lower accuracy than did control activities $(M=1.21)[t(63)=$ $1.34, p=.19]$.

To understand more precisely how eye movements affected recognition accuracy, we analyzed hits and false alarms separately. In the analysis of hits, there were no significant effects (smallest $p=.22$ ), but Figure 4 shows that, for SR subjects, eye movements increased hits $(M=$ $.72)$ in comparison with control conditions $(M=.66)$. This difference, by itself, was marginally significant $[t(87)=$ $1.79, p=.08]$. For $\mathrm{nSR}$, hits were equivalent in the eyemovement $(M=.69)$ and control $(M=.70)$ conditions.

In false alarms, there was a significant interaction of handedness and eye movements $[F(1,150)=9.02, p=$ $\left..03, \eta_{\mathrm{p}}^{2}=.06\right]$. As is shown in Figure 5, false alarms were marginally lower for SR subjects following eye movements $(M=.24)$ than following control activities $(M=$ .29) $[t(87)=1.76, p=.082]$, whereas there was a significant difference in the opposite direction for nSR subjects $(M \mathrm{~s}=.37$ and .28 , respectively) $[t(63)=2.39, p=.02]$. The latter finding, like that of increased false recall in Experiment 1 , indicates, unexpectedly, that eye movements can harm retrieval for $\mathrm{nSR}$ individuals.

To summarize, both horizontal and vertical saccades enhanced recognition accuracy for SR subjects by simultaneously increasing hits and decreasing false alarms. In contrast, for nSR subjects, eye movements did not affect hits and significantly increased false alarms.

In proposing the hemispheric interaction theory, Christman et al. (2003) highlighted evidence that horizontal saccades increase bihemispheric activation; thus, our finding that vertical saccades also affect subsequent retrieval may appear to challenge the theory. However, we suggest that vertical saccades also may increase bihemispheric activation. Repetitive saccades (and/or concomitant shifts of attention) are associated with bilateral activation of the frontal eye field (Rosano et al., 2002), and, given the bilateral nature of the motor activity, this presumably holds whenever the eyes move together, regardless of direction. Therefore, it may be that bilateral activation of the frontal eye field, which is critically involved in attention (Moore \& Fallah, 2004), is produced by both horizontal and vertical saccades and, in either case, leads to increased bilateral activation of other, interconnected brain regions, thereby increasing hemispheric interaction.

Handedness and memory. Propper and Christman (2004) found no handedness difference in recognition

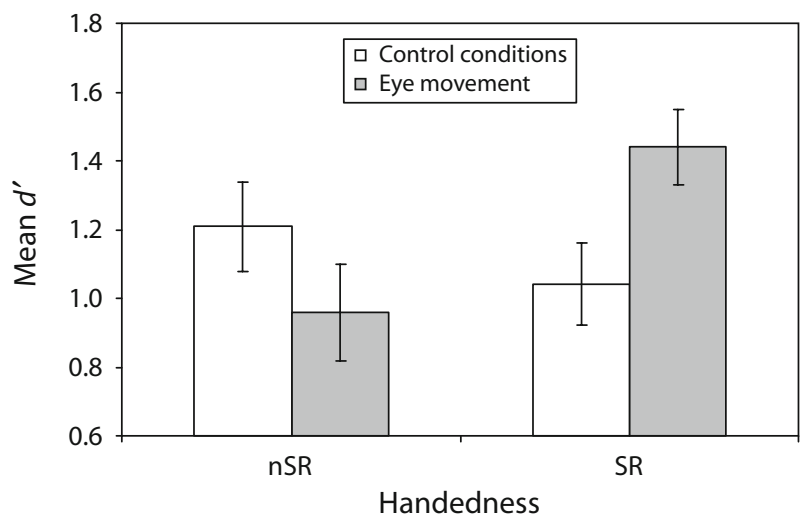

Figure 3. Mean $d^{\prime}$ in Experiment 2 as a function of handedness and pretest activity. Control condition means are based on data from subjects in the no-movement and spontaneous-movement conditions. Eye-movement means are based on data from subjects in the vertical-movement and horizontal-movement conditions. Error bars represent \pm 1 standard error.

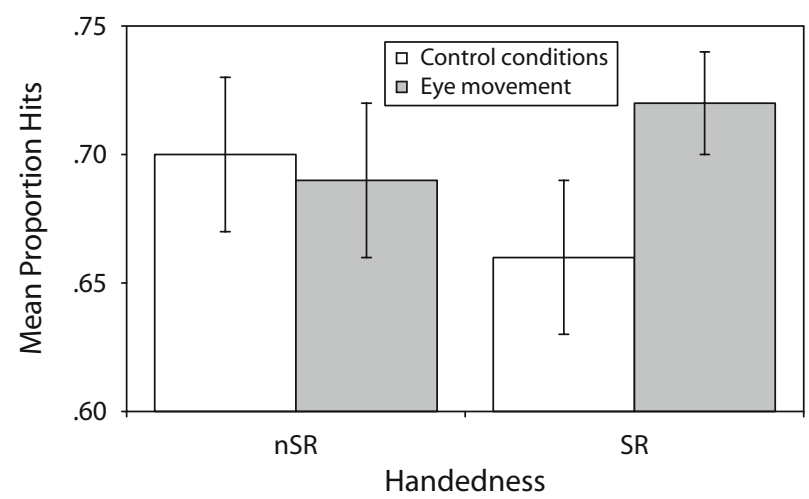

Figure 4. Mean proportion hits in Experiment 2 as a function of handedness and pretest activity. Control conditions means are based on data from subjects in the no-movement and spontaneousmovement conditions. Eye-movement means are based on data from subjects in the vertical-movement and horizontal-movement conditions. Error bars represent \pm 1 standard error.

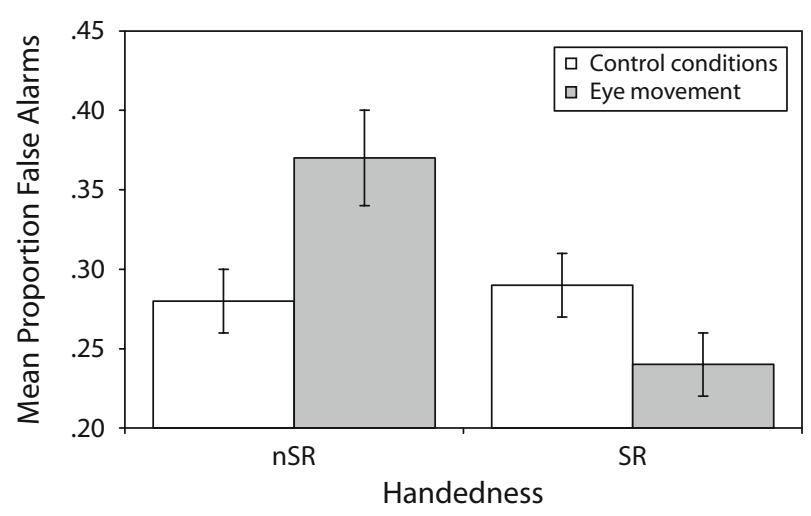

Figure 5. Mean proportion false alarms in Experiment 2 as a function of handedness and pretest activity. Control condition means are based on data from subjects in the no-movement and spontaneous-movement conditions. Means labeled Eye-movement means are based on data from subjects in the vertical-movement and horizontal-movement conditions. Error bars represent \pm 1 standard error. 
memory in the absence of eye movements. Similarly, in the no-movement condition here, $d^{\prime}$ did not differ significantly between $\mathrm{nSR}(M=.42)$ and $\mathrm{SR}(M=.37)$ subjects $[t(75)=0.99, p=.32]$.

\section{GENERAL DISCUSS.ION}

Repetitive saccadic eye movements immediately before a memory test enhanced subsequent retrieval relative to a no-movement condition (Experiments 1 and 2) and to natural, spontaneous eye movements (Experiment 2). Strikingly, though, eye movements benefited only SR subjects; nSR subjects did not show eye-movement enhancement on any measure of retrieval. In fact, the only eye-movement effects for nSR subjects were negative ones. For SR subjects, eye movements increased correct recall and true recognition (hits) and reduced false recall and false recognition (false alarms). For nSR subjects, eye movements had no effect on correct recall or hits, but increased false recall and false alarms. Thus, in both recall and recognition, eye movements can be a potent memory enhancer-both increasing true memory and decreasing false memory (see Christman et al., 2003, Experiment 1; Parker \& Dagnall, 2007, for the same dual effects) - but only for SR individuals. Eye movements do not affect true memory for nSR individuals, and they actually increase false memory.

Given evidence that baseline hemispheric interaction is less in SR than in nSR individuals (Cowell et al., 1993; Habib et al., 1991; Witelson, 1985), the present results are partially supportive of the theory that eye movements enhance retrieval by increasing hemispheric interaction (Christman et al., 2003), because that theory predicts that eye movements should benefit SR individuals more than nSR individuals. This prediction was borne out: SR subjects benefited from eye movements on several measures, whereas nSR subjects benefited on none.

The hemispheric interaction theory predicts unequal benefits of eye movements for persons of different handedness, but, given the key assumption that hemispheric interaction benefits retrieval, it cannot explain our finding that eye movements harmed retrieval for nSR subjects by increasing false recall and recognition. Therefore, we propose the following, admittedly speculative, amendment: Hemispheric interaction may benefit retrieval only up to a point, and past that point, it may impair retrieval. Thus, persons with a high baseline amount of interaction, such as nSR individuals, may be harmed by the increase caused by eye movements.

Why might hemispheric interaction impair retrieval? Theoretically, interaction benefits retrieval because certain retrieval processes are carried out more by one hemisphere than by the other; such is the case with production of information in the left and monitoring of information in the right (Cabeza, Locantore, \& Anderson, 2003) or monitoring of specific memory characteristics in the left and monitoring of undifferentiated information in the right (Mitchell, Johnson, Raye, \& Greene, 2004). Therefore, hemispheric interaction is necessary for the coordination of these processes. However, the hemispheres are also dif- ferentially involved in language processing, with the right maintaining broader, more distant, meanings than the left (Jung-Beeman, 2005). In other words, the right hemisphere may maintain related, but nonpresented, information. Perhaps, past some point, the benefits of increased hemispheric interaction that come from more efficient coordination of retrieval processes are offset by increased access to related but nonpresented semantic information in the right hemisphere, which could be falsely recalled or recognized (Faust, Ben-Artzi, \& Harel, in press; Roediger, Watson, McDermott, \& Gallo, 2001). Regarding this, note that the lures in Experiment 2, which nSR subjects falsely recognized more often following eye movements, were associated with or related to studied items.

Additional work, including investigating the neural networks underlying retrieval following eye movements, is needed to determine more precisely how and why eye movements influence retrieval in various populations. For now, we caution that, although eye movements may hold promise as a simple memory-enhancement technique for some individuals, they may prove detrimental for others.

\section{AUTHOR NOTE}

Results of this study were presented in part at the Annual Meeting of the Psychonomic Society (Houston, November 2006). We thank Pooja K. Agarwal, Jeffrey L. Heitman, and Brittany L. Scott for their assistance with data collection. Correspondence concerning this article should be addressed to K. B. Lyle, Department of Psychological and Brain Sciences, University of Louisville, Louisville, KY 40292 (e-mail: keith .lyle@louisville.edu).

\section{REFERENCES}

BAKAN, P., \& Svorad, D. (1969). Resting EEG alpha asymmetry of reflective lateral eye movements. Nature, 223, 975-976.

Balota, D. A., Cortese, M. J., Hutchinson, K. A., Neely, J. H., Nelson, D., Simpson, G. B., \& Treiman, R. (2002). The English Lexicon Project: A web-based repository of descriptive and behavioral measures for 40,481 English words and nonwords. Retrieved October, 2005, from elexicon.wustl.edu/, Washington University.

Cabeza, R., Locantore, J. K., \& Anderson, N. D. (2003). Lateralization of prefrontal activity during episodic memory retrieval: Evidence for the production-monitoring hypothesis. Journal of Cognitive Neuroscience, 15, 249-259.

Christman, S. D., Garvey, K. J., Propper, R. E., \& Phaneuf, K. A. (2003). Bilateral eye movements enhance the retrieval of episodic memories. Neuropsychology, 17, 221-229.

Christman, S. D., Propper, R. E., \& Brown, T. J. (2006). Increased interhemispheric interaction is associated with earlier offset of childhood amnesia. Neuropsychology, 20, 336-345.

Christman, S. D., Propper, R. E., \& Dion, A. (2004). Increased interhemispheric interaction is associated with decreased false memories in a verbal converging semantic associates paradigm. Brain \& Cognition, 56, 313-319.

Cowell, P. E., Kertesz, A., \& Denenberg, V. H. (1993). Multiple dimensions of handedness and the human corpus callosum. Neurology, 43, 2353-2357.

Faust, M., Ben-Artzi, E., \& Harel, I. (in press). Hemispheric asymmetries in semantic processing: Evidence from false memories for ambiguous words. Brain \& Language.

Habib, M., Gayraud, D., Oliva, A., Regis, J., Salamon, G., \& KHALIL, R. (1991). Effects of handedness and sex on the morphology of the corpus callosum: A study with brain magnetic resonance imaging. Brain \& Cognition, 16, 41-61.

JänCKe, L., \& Steinmetz, H. (2003). Brain size: A possible source of interindividual variability in corpus callosum morphology. In E. Zaidel \& M. Iacoboni (Eds.), The parallel brain: The cognitive 
neuroscience of the corpus callosum (pp. 51-63). Cambridge, MA: MIT Press.

Johnson, M. K., \& RAYE, C. L. (2000). Cognitive and brain mechanisms of false memories and beliefs. In D. L. Schacter \& E. Scarry (Eds.), Memory, brain, and belief (pp. 35-86). Cambridge, MA: Harvard University Press.

JUNG-BEEMAN, M. (2005). Bilateral brain processes for comprehending natural language. Trends in Cognitive Sciences, 9, 712-718.

Kertesz, A., Polk, M., Howell, J., \& Black, S. E. (1987). Cerebral dominance, sex, and callosal size in MRI. Neurology, 37, 1385-1388.

Lyle, K. B., McCabe, D. P., \& Roediger, H. L., III (in press). Handedness is related to memory via hemispheric interaction: Evidence from paired associate recall and source memory tasks. Neuropsychology.

Mitchell, K. J., Johnson, M. K., Raye, C. L., \& Greene, E. J. (2004). Prefrontal cortex activity associated with source monitoring in a working memory task. Journal of Cognitive Neuroscience, 16, 921-934.

Moore, T., \& Fallah, M. (2004). Microstimulation of the frontal eye field and its effects on covert spatial attention. Journal of Neurophysiology, 91, 152-162.

Nolde, S. F., Johnson, M. K., \& RaYe, C. L. (1998). The role of the prefrontal cortex during tests of episodic memory. Trends in Cognitive Sciences, 2, 399-406.

OLDFIELD, R. (1971). The assessment and analysis of handedness: The Edinburgh Inventory. Neuropsychologia, 9, 97-113.

Parker, A., \& Dagnall, N. (2007). Effects of bilateral eye movements on gist based false recognition in the DRM paradigm. Brain \& Cognition, 63, 221-225.
Phelps, E. A., Hirst, W., \& Gazzaniga, M. S. (1991). Deficits in recall following partial and complete commissurotomy. Cerebral Cortex, 1, 492-498.

Propper, R. E., \& Christman, S. D. (2004). Mixed- versus strong righthandedness is associated with biases towards "remember" versus "know" judgements in recognition memory: Role of interhemispheric interaction. Memory, 12, 707-714.

Propper, R. E., Christman, S. D., \& Phaneuf, K. A. (2005). A mixedhanded advantage in episodic memory: A possible role of interhemispheric interaction. Memory \& Cognition, 33, 751-757.

Propper, R. E., Pierce, J., Bellorado, N., Geisler, M. W., \& ChristMAN, S. D. (2007). Effect of bilateral eye movements on frontal interhemispheric gamma EEG coherence: Implications for EMDR therapy. Journal of Nervous \& Mental Disease, 195, 785-788.

Roediger, H. L., III, Watson, J. M., McDermott, K. B., \& Gallo, D. A. (2001). Factors that determine false recall: A multiple regression analysis. Psychonomic Bulletin \& Review, 8, 385-407.

Rosano, C., Krisky, C. M., Welling, J. S., Eddy, W. F., Luna, B., Thulborn, K. R., \& Sweeney, J. A. (2002). Pursuit and saccadic eye movement subregions in human frontal eye field: A high-resolution fMRI investigation. Cerebral Cortex, 12, 107-115.

WiTELSON, S. F. (1985). The brain connection: The corpus callosum is larger in left-handers. Science, 229, 665-668.

ZAIDEL, D., \& SPERRY, R. W. (1974). Memory impairments after comissurotomy in man. Brain, 97, 263-272.

(Manuscript received July 22, 2007;

revision accepted for publication December 21, 2007.) 